\author{
Andrew Schiff', Brenna L Brady ${ }^{2 *}$, \\ Sudip K Ghosh ${ }^{1}$, Sanjoy Roy ${ }^{1}$, Charles \\ Ruetsch $^{2}$ and Elliott Fegelman ${ }^{1}$ \\ ${ }^{1} J o h n s o n$ \& Johnson Medical Devices Cincinnati, \\ $\mathrm{OH}, \mathrm{USA}$ \\ ${ }^{2}$ Health Analytics, LLC Columbia, MD, USA
}

Dates: Received: 25 June, 2016; Accepted: 23 July, 2016; Published: 25 July, 2016

*Corresponding author: Brenna L Brady, PhD, Health Analytics, LLC Columbia, 9200, Rumsey

Rd Suite 215, Columbia, MD, 21045, USA, E-mail: bbrady@healthanalytic.com

www.peertechz.com

ISSN: 2455-2968

Keywords: Colorectal resection; Anastomotic leakage; Anastomotic integrity test; Intra-operative

\section{Review Article \\ Intra-Operative Anastomotic Leak Rates and Testing Methodology in Colorectal Resection Surgery}

\begin{abstract}
Purpose: Anastomotic leak following colorectal resection surgery is associated with high rates of morbidity, infection, and escalated healthcare expenditures. One method to prevent leaks includes early detection through intra-operative testing. This study employed systematic review of the literature to estimate the rate of intra-operative anastomotic leaks in colorectal resection surgery.

Method: The Medline and Embase databases were searched to identify articles published between January $1^{\text {st }}, 2003$ and August $8^{\text {th }}, 2015$ reporting on intra-operative leaks in colorectal resection. The rate of intra-operative testing, intra- and post-operative anastomotic leaks, and surgical methodology were extracted from the final sample of 13 articles.

Results: A total of 167 intra-operative leaks were reported within 2,598 colorectal resection surgeries that used intra-operative testing, yielding an average leak rate of $6.4 \%$. Use of laparoscopic techniques was significantly associated with a reduced rate of intra-operative leak $(p<0.001)$. Eight articles reported on the rate of post-operative anastomotic leak in relation to intraoperative testing. Within this sample of 2,098 cases a non-significant trend towards a lower leak rate in the tested population was identified $(4.3 \%$ v. $6.8 \%, p=0.051)$; cases whose leak test was initially positive exhibited a significantly higher rate of post-operative leaks compared to cases with a negative leak test $(p=0.006)$.

Conclusion: Intra-operative anastomotic leak testing allows surgeons to address leaks at the time of surgery, and may help to prevent complications in colorectal resection surgery. This study identified a mean intra-operative leak rate of $6.4 \%$ in colorectal resection surgery.
\end{abstract}

\section{Background}

Anastomotic leaks are one of the most feared outcomes of colorectal resection surgery, as they result in poor patient outcomes, extended hospital stays, increased cost of care, and a high rate of mortality [1-5]. Complications of anastomotic leaks can include infection, fistula or abscess formation, and peritonitis [6]. In cases of malignancy, presence of anastomotic leaks are also associated with increased rates of local cancer recurrence and decreased five year survival $[2,7,8]$. Intra-operative leak testing is routinely performed as a prognostic approach to assess anastomotic integrity. Positive intraoperative leak tests are addressed during surgery through additional suturing, sealant, re-anastomosis, or diversion and stoma creation [9]. Conversely, leaks identified post-operatively, that cannot be treated with antibiotics, require secondary procedures including percutaneous or surgical draining of abscesses or secondary surgery to correct the leak [6], the need for creation of a permanent stoma is also increased in these cases [10]. Prevention of mortality due to anastomotic leak is largely dependent upon early detection and treatment of leaks $[6,11]$. Aside from being a leading cause of postoperative death in colorectal surgery, anastomotic leaks increased the need for secondary surgeries and hospital re-admissions [1,1214]. Estimates indicate that anastomotic leaks add an additional \$28.6 million in healthcare costs for every 1,000 patients undergoing colorectal surgery [13]. These increased expenditures are largely due to increased need for post-operative care following the incidence of an anastomotic leak, which can be extensive. Therefore prevention and early detection of anastomotic leaks, potentially though improved surgical techniques and the use of intra-operative testing respectively, is crucial to improve patient outcomes, prevent mortality, and contain healthcare costs.

The use of intra-operative leak testing allows the surgeon to test the integrity of the anastomosis shortly after creation, thus providing the opportunity for immediate repair or diversion of compromised anastomoses. There are multiple methodologies for intra-operative leak testing including endoscopy or insufflation of the anastomosis with methylene blue, povidone-iodine, saline, or air [15]. Although, intra-operative testing addresses anastomotic integrity at the point of anastomosis creation, it is not able or intended to completely prevent post-operative anastomotic leaks, as some leaks develop post-operatively due to compromised gastrointestinal healing or other unknown factors. However, studies have shown that the use of intra-operative leak testing has been effective in reducing some post-operative leaks and complications of colorectal surgery $[1,16]$. Although clinical guidelines remain largely silent on the use of intraoperative leak testing in colorectal resection surgery, multiple studies have called for routine use of intra-operative testing in resection surgery $[15,17,18]$.

The purpose of this study was to estimate the prevalence of intra-operative leaks in colon resection surgery using the recently published literature. The rate of intra-operative leak testing, as well as the reported rate of anastomotic leaks, was identified within a sample 
of articles that reported on leak tests in colorectal resection surgery; all types of intraoperative leak testing were included in this review. Where reported, the correlation between intra-operative testing and post-operative anastomotic leak was also explored, as was the association between anastomosis type (e.g. stapled versus sutured) and intra-operative leak.

\section{Methods}

\section{Search methods and procedures}

A systematic search of the Medline and Embase databases was performed to identify articles reporting on the use of intra-operative leak testing in colon resection surgery. Search criteria were developed based on a preliminary assessment of peer-reviewed literature with assistance from a panel of experts on the surgical treatment of gastroenterological diseases.

\section{Search terms}

The search terms included the intervention, the population being studied, and the primary outcome of the review (Table 1). The search was limited to publication dates between January 1, 2003 and August 8,2015 , as the focus of this study was to assess the current rate of intra-operative anastomotic leak.

\section{Types of studies}

Randomized controlled trials (RCTs), prospective outcome studies, clinical trials, comparative studies, evaluations, and observational studies were included in the final sample of articles. Editorials, letters to the editor, conference abstracts without publication follow-up, and experiential non-empirical articles were excluded.

\section{Study participants}

Articles included adult humans, and all included articles discussed the use of anastomosis in colorectal resection surgery.

\section{Measures}

Primary study outcomes included study sample size, type(s) of anastomosis method employed, rate of intra-operative testing, rate

\begin{tabular}{|c|c|}
\hline \multicolumn{2}{|l|}{ Search Term } \\
\hline Description & Definition \\
\hline Colon & $\begin{array}{l}\text { colon, OR colonic, OR colorectal, OR rectal, OR rectum, OR } \\
\text { "lower anterior resection", OR "low anterior resection", OR "LAR } \\
\text { sigmoidectomy", OR "left hemicolectomy", OR "total mesorectal } \\
\text { excision", OR TME }\end{array}$ \\
\hline Intraoperative & $\begin{array}{l}\text { intraoperative, OR "intra-operative", OR perioperative, OR "peri- } \\
\text { operative" }\end{array}$ \\
\hline Leak & $\begin{array}{l}\text { complication, OR abscess, OR leak, OR anastomosis, OR infec- } \\
\text { tion, OR ileus, OR bleeding, OR transfusion, OR cost, OR sepsis, } \\
\text { OR ureter, OR hernia, OR obstruction, OR recurrence, OR TPN, } \\
\text { OR "total parenteral nutrition" }\end{array}$ \\
\hline \multicolumn{2}{|l|}{ Filters } \\
\hline Date Range & 1/1/2003 - 8/8/2015 \\
\hline Language & English \\
\hline Age & $18-64$ \\
\hline
\end{tabular}

of intra-operative leaks, and rate of post-operative leaks. Articles were required to include these five primary study variables. The type of anastomosis closure method employed was extracted for the total study sample, rate of intra-operative testing, rate of intra-operative leaks, and rate of post-operative leaks were available to facilitate subgroup analyses; studies were not required to report the type of closure used by subgroup.

\section{Screening and reviewing process}

The search returned a total of $\mathrm{N}=424$ articles. All articles were screened for study eligibility criteria by two independent reviewers; any discrepancies between the two reviewers were reconciled by a third reviewer. All articles were required to report on intra-operative leak rates during colon resection surgery. The screening process was initiated with an abstract review; articles were included if they referenced the prevalence of intra-operative leaks in colon resection surgery. A full text review was then conducted for those articles that passed the abstract review $(n=89)$; articles that did not report rates of intra-operative leak in either the text or results table were excluded. The screening and review phases, led to exclusion of 411 publications leaving 13 studies in the final review (Table 2).

Data, including author, title, date, journal, year of publication, and primary study outcomes and were extracted by two independent reviewers. All discrepancies were resolved by an independent third party.

\section{Statistical analyses}

For each of the 13 studies included in the review, frequencies were reported for the total sample and for the subsamples receiving each type of anastomosis. Additionally, within each anastomosis group, the frequency in which intra-operative testing was performed, intra-operative leaks were discovered, and post-operative leaks were discovered were all reported where available. Intra-operative and post-operative leakage rates were examined as a function of anastomosis type, surgical type, the presence of leak testing, and the result of leak testing by pooling data across all studies. Statically significant differences in leakage rates were assessed by chi square tests of equality of proportions. Pairwise comparisons were examined where significant omnibus tests of anastomosis type were achieved. Statistical analyses were conducted with SPSS (version 20, Chicao, IL), and a critical alpha level of 0.05 was set.

\section{Results}

The thirteen reviewed studies included a total of $\mathrm{N}=3,023$ patients (Table 3), [16,17,19-29]. Study sample size and design was variable. Two studies (Ivanov et al. and Lieto et al.,) used a controlled design that included an intra-operative testing group and a no intraoperative testing control group. Li et al., also used a controlled design, but testing was employed in the control based on specific clinical indications during surgery. Two studies (Leahy et al., Riccardi et al.,) left the decision to use intra-operative testing to the surgeon. The final nine studies all employed a study protocol where intra-operative leak testing was required. Sample size varied from a low of $\mathrm{N}=20$ patients in Sherwinter et al., to $\mathrm{N}=998$ patients in Riccardi et al. 
Table 2: Included Articles.

\begin{tabular}{|c|c|c|c|}
\hline First Author & Title & Journal & Year \\
\hline Chen [30] & $\begin{array}{l}\text { Intra-operative anastomotic dye } \\
\text { test significantly decreases in- } \\
\text { cidence of anastomotic leaks in } \\
\text { patients undergoing resection for } \\
\text { rectal cancer }\end{array}$ & $\begin{array}{l}\text { Techniques in Colo- } \\
\text { proctology }\end{array}$ & 2013 \\
\hline Dauser [19] & $\begin{array}{l}\text { Anastomotic leakage after low } \\
\text { anterior resection for rectal can- } \\
\text { cer: comparison of stapled versus } \\
\text { compression anastomosis. }\end{array}$ & $\begin{array}{l}\text { Langenbecks Ar- } \\
\text { chives of Surgery }\end{array}$ & 2013 \\
\hline Ishihara [20] & $\begin{array}{l}\text { Intra-operative colonoscopy for } \\
\text { stapled anastomosis in colorectal } \\
\text { surgery. }\end{array}$ & Surgery Today & 2008 \\
\hline Ivanov [21] & $\begin{array}{l}\text { Intra-operative air testing of } \\
\text { colorectal anastomoses. }\end{array}$ & $\begin{array}{l}\text { Srpski Arhiv za Ce- } \\
\text { lokupno Lekarstvo }\end{array}$ & 2011 \\
\hline Lanthaler [22] & $\begin{array}{l}\text { Intra-operative colonoscopy for } \\
\text { anastomosis assessment in lapa- } \\
\text { roscopically assisted left-sided } \\
\text { colon resection: is it worthwhile? }\end{array}$ & $\begin{array}{l}\text { Journal of Lapa- } \\
\text { roendoscopic and } \\
\text { Advanced Surgical } \\
\text { Techniques }\end{array}$ & 2008 \\
\hline Li [24] & $\begin{array}{l}\text { Use of routine intra-operative en- } \\
\text { doscopy in elective laparoscopic } \\
\text { colorectal surgery: can it further } \\
\text { avoid anastomotic failure? }\end{array}$ & Surgical Endoscopy & 2009 \\
\hline Leahy [23] & $\begin{array}{l}\text { What Is the Risk of Clinical } \\
\text { Anastomotic Leak in the Diverted } \\
\text { Colorectal Anastomosis? }\end{array}$ & $\begin{array}{l}\text { Journal of Gastroin- } \\
\text { testinal Surgery }\end{array}$ & 2014 \\
\hline Lieto [25] & $\begin{array}{l}\text { Endoscopic Intra-operative Anas- } \\
\text { tomotic Testing May Avoid Early } \\
\text { Gastrointestinal Anastomotic } \\
\text { Complications: a Prospective } \\
\text { Study }\end{array}$ & $\begin{array}{l}\text { Journal of Gastroin- } \\
\text { testinal Surgery }\end{array}$ & 2011 \\
\hline Ricciardi [16] & $\begin{array}{l}\text { Anastomotic leak testing after } \\
\text { colorectal resection: what are the } \\
\text { data? }\end{array}$ & Archives of Surgery & 2009 \\
\hline Shamiyeh [26] & $\begin{array}{l}\text { Intra-operative endoscopy for the } \\
\text { assessment of circular-stapled } \\
\text { anastomosis in laparoscopic colon } \\
\text { surgery. }\end{array}$ & $\begin{array}{l}\text { Surgical Laparos- } \\
\text { copy, Endoscopy } \\
\text { and Percutaneous } \\
\text { Tehcniques }\end{array}$ & 2012 \\
\hline Sherwinter [27] & $\begin{array}{l}\text { Intra-operative transanal near } \\
\text { infrared imaging of colorectal } \\
\text { anastomotic perfusion: a feasibil- } \\
\text { ity study. }\end{array}$ & Colorectal Dis. & 2013 \\
\hline Smith [28] & $\begin{array}{l}\text { The efficacy of intra-operative } \\
\text { methylene blue enemas to assess } \\
\text { the integrity of a colonic anasto- } \\
\text { mosis. }\end{array}$ & BMC Surgery & 2007 \\
\hline Xiao [29] & $\begin{array}{l}\text { Can transanal tube placement } \\
\text { after anterior resection for rectal } \\
\text { carcinoma reduce anastomotic } \\
\text { leakage rate? A single-institution } \\
\text { prospective randomized study. }\end{array}$ & $\begin{array}{l}\text { World Journal of } \\
\text { Surgery }\end{array}$ & 2011 \\
\hline
\end{tabular}

Stapling was the primary method of anastomosis creation across studies, with $n=2,712$ patients ( $89.7 \%$ ) receiving a stapled anastomosis (Table 3). Hand sewn sutured anastomosis was used in a total of $\mathrm{n}=273$ cases $(9.0 \%)$ and a compression anastomosis was employed in the remaining $\mathrm{n}=38$ cases $(1.3 \%)$. Seven studies required that staple anastomosis be employed [20-22,24-27], while the remaining six studies allowed multiple methods of anastomosis closure. Within these six studies that employed multiple anastomosis methods $[16,19,23,28-30]$, stapled anastomosis was always one of the methods used. Five of these six studies used either staple or suture based anastomosis, while the remaining study (Dauser et al.) employed either a staple or compression anastomosis closure. Nine articles reported on the use of open and laparoscopic surgical techniques $[19,21,22,24-27,29]$. Within this sample of $n=1,649$ cases, $n=882$ (54.1\%) were performed using laparoscopic techniques. Two studies (Lieto et al., Xiao et al.) only performed open procedures, while four studies (Lanthaler et al., Li et al., Shamiyeh et al., and Sherwinter et al.) required use of laparoscopic techniques.

Intra-operative anastomotic leak testing was widely used with a total of $n=2,598(85.9 \%)$ patients receiving intra-operative testing (Table 4). Eight studies required the use of intraoperative testing as part of the study protocol. Presence of leak testing across the 13 studies ranged from a rate of $45.2 \%$ in Lieto et al., which included a no test control group, to $100 \%$ in the eight studies, which required the use of intra-operative leak testing [19,20,22,26-30]. The rate of intraoperative testing observed in the two studies (Riccardi et al., Leahy et al.) where the decision to test was left up to the surgeon was $82.3 \%$ (1,243 of 1,023 patients). Of those patients who received testing, $84.8 \%$ had a stapled anastomosis, $6.0 \%$ had a sutured anastomosis, and $1.5 \%$ received a compression anastomosis.

Within this total sample of $n=2,598$ patients who received an intra-operative leak test a total of 167 leaks were identified, resulting in a mean intra-operative leak rate of $6.4 \%$ across the 13 studies (Table 4). Rates of intra-operative leaks ranged from $0.0 \%$ in Sherwinter et al., to $23.3 \%$ in Ivanov et al. All but one of the studies (Leahy et al.) reported on the method of anastomosis repair. Suture repair $(74.7 \%)$ was the most common method of anastomosis correction used followed by takedown and re-anastomosis (17.3\%) and diversion (8.0\%). No significant differences in intraoperative leak rates were found were found across anastomosis types (staple: $4.9 \%$, suture: $2.3 \%$, and compression: $0.0 \%, \mathrm{p}=0.066$ ) in the 10 studies that reported leak based on type of anastomosis employed [16,19-22,2428]. Six articles reported on the rate of intraoperative leaks by surgical technique used (laparoscopic v. open) [22,25-29]. Within this sample of $n=1,163$ the majority of procedures (57.6\%) were performed using an open technique. Intraoperative anastomotic leak rates significantly higher in open procedures compared to laparoscopic procedures (6.7\% v. $2.4 \%, \mathrm{p}<0.001)$.

The rate of post-operative anastomotic leaks across the total study sample was $5.2 \%$ (Table 4). Across studies post-operative leak rates ranged from $0.8 \%$ in $\mathrm{Li}$ et al., to $15.0 \%$ in Ivanov et al. The rate of post-operative leaks was significantly different across anastomosis types in $\mathrm{n}=2,947$ cases (staple: $5.1 \%$, suture: $9.7 \%$, and compression: $5.3 \%, p=0.009$ ), with a significantly lower post-operative leak rate in stapled compared to suture anastomosis $(\mathrm{p}=0.002)$. The study by Chen et al., was excluded from this assessment of post-operative leak rate by study type, as the number of total post-operative leaks were not presented for anastomosis subgroups. Seven articles reported on the rate of post-operative leaks by surgical technique [19,22,25-29]. In the sample of $n=1,589$ cases the majority of procedures $(55.2 \%)$ were performed using laparoscopic techniques. The rate of post-operative anastomotic leak remained significantly higher in the open procedure group compared to the laparoscopic procedure group (6.3\% v. $2.5 \%$, $\mathrm{p}<0.001)$.

The association between use of intra-operative testing and post-operative anastomotic leak was only reported in eight of the 13 studies. Within these eight studies 97 post-operative leaks were identified in 2,098 patients, resulting in a post-operative leak rate of 


\begin{tabular}{|c|c|c|c|c|c|c|c|c|c|c|c|c|c|c|c|c|c|}
\hline \multirow{4}{*}{ 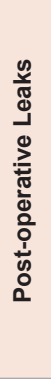 } & \multirow{3}{*}{ 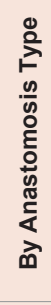 } & 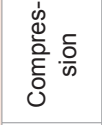 & 0 & $N$ & 0 & 0 & 0 & 0 & 0 & 0 & 0 & 0 & 0 & 0 & 0 & $N$ & \\
\hline & & $\begin{array}{l}0 \\
\stackrel{0}{5} \\
\stackrel{5}{5} \\
\omega\end{array}$ & $\frac{\alpha}{z}$ & $\circ$ & 0 & 0 & 0 & $\wedge$ & 0 & 0 & $\infty$ & 0 & 0 & $\nabla$ & $m$ & $\approx$ & \\
\hline & & $\begin{array}{l}\frac{0}{2} \\
\frac{\pi}{\omega}\end{array}$ & $\frac{\mathscr{r}}{z}$ & $\wedge$ & - & $\sigma$ & 0 & $\hat{\sim}$ & $N$ & $a$ & ㅇ & 10 & $\sim$ & $m$ & $\stackrel{\sim}{\sim}$ & 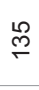 & \\
\hline & & 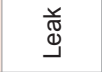 & - & $\sigma$ & $r$ & $\sigma$ & 0 & ले & $\sim$ & $\sigma$ & $\stackrel{\infty}{\stackrel{\infty}{\sim}}$ & 10 & $\sim$ & $\wedge$ & $\hat{\sim}$ & $\stackrel{\circ}{\circ}$ & \\
\hline \multirow{4}{*}{ 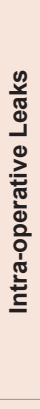 } & \multirow{3}{*}{ 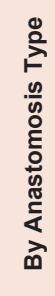 } & 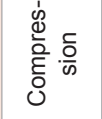 & 0 & 0 & 0 & 0 & 0 & 0 & 0 & 0 & 0 & 0 & 0 & 0 & 0 & 0 & \\
\hline & & $\begin{array}{l}0 \\
\stackrel{0}{5} \\
⿱ 士 5 \\
\omega\end{array}$ & $\frac{\alpha}{z}$ & 0 & 0 & 0 & 0 & 品 & 0 & 0 & $\sim$ & 0 & 0 & $\nabla$ & 品 & 0 & \\
\hline & & $\begin{array}{l}\frac{0}{0} \\
\frac{\pi}{\omega 0} \\
\frac{10}{3}\end{array}$ & $\frac{\underline{\alpha}}{z}$ & - & $\nabla$ & $\wedge$ & ம & $\frac{\alpha}{z}$ & $m$ & 0 & $\mathscr{\varnothing}$ & $\sim$ & 0 & $\stackrel{\simeq}{\simeq}$ & $\frac{\mathscr{r}}{z}$ & 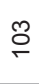 & \\
\hline & & 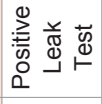 & $\mp$ & - & $\nabla$ & $\wedge$ & L & $\approx$ & $m$ & 0 & ஜூ & $\sim$ & 0 & $\stackrel{\varphi}{\circ}$ & ి్ల & $\hat{\theta}$ & \\
\hline \multirow{4}{*}{ 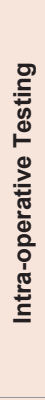 } & \multirow{3}{*}{ 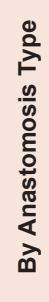 } & 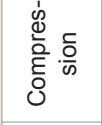 & 0 & $\stackrel{\infty}{\infty}$ & 0 & 0 & 0 & 0 & 0 & 0 & 0 & $\circ$ & 0 & 0 & 0 & $\stackrel{\infty}{\infty}$ & \\
\hline & & $\begin{array}{l}\stackrel{0}{=} \\
\stackrel{5}{5} \\
\omega\end{array}$ & $\stackrel{2}{\sim}$ & 0 & 0 & 0 & 0 & $\frac{\alpha}{z}$ & 0 & 0 & $\bar{\sim}$ & 0 & 0 & 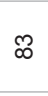 & $\stackrel{\infty}{\sim}$ & in & \\
\hline & & $\frac{\frac{0}{2}}{\frac{\pi}{\omega}}$ & in & $\stackrel{\infty}{\infty}$ & $\Re$ & ஜ) & 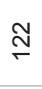 & $\frac{\alpha}{z}$ & $\stackrel{\hat{m}}{\sim}$ & $\mathscr{b}$ & ఫ్ర & $\stackrel{\infty}{\text { ల్ల }}$ & ํ & $\stackrel{\mathscr{P}}{\sim}$ & ? & 苂 & \\
\hline & & 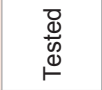 & $\stackrel{\bullet}{\sim}$ & ஜூ & $\stackrel{\Re}{\wedge}$ & ஓे & 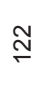 & $\stackrel{\infty}{\circ}$ & $\stackrel{\hat{m}}{\sim}$ & $\underset{1}{6}$ & $\stackrel{\infty}{\stackrel{\infty}{2}}$ & 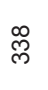 & $\stackrel{N}{ }$ & $\underset{N}{\mathbb{N}}$ & 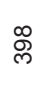 & $\begin{array}{l}\text { 足 } \\
\stackrel{\circ}{N} \\
\stackrel{N}{*}\end{array}$ & \\
\hline \multirow{8}{*}{ 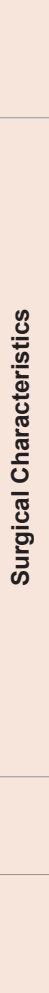 } & & 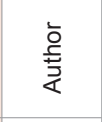 & $\frac{\bar{\Phi}}{\frac{\Phi}{U}}$ & 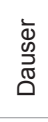 & 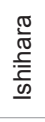 & $\begin{array}{l}\text { ठे } \\
\stackrel{0}{\mathbb{1}} \\
\geq\end{array}$ & 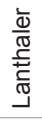 & $\begin{array}{l}\overrightarrow{\mathbb{\Phi}} \\
\stackrel{\Phi}{\Phi}\end{array}$ & ב & $\frac{0}{\stackrel{0}{\underline{U}}}$ & $\begin{array}{l}\overline{\overline{0}} \\
\overline{\frac{0}{0}} \\
\overline{0} \\
\overline{0}\end{array}$ & $\begin{array}{l}\frac{c}{\Phi} \\
\stackrel{\grave{\hat{\varepsilon}}}{\bar{\sigma}} \\
\frac{\bar{\sigma}}{\omega}\end{array}$ & $\frac{\sum_{0}^{\prime}}{\frac{1}{\omega}}$ & $\begin{array}{l}\text { 呈 } \\
\text { 心 }\end{array}$ & $\stackrel{\stackrel{0}{\pi}}{\stackrel{\mathscr{x}}{x}}$ & $\begin{array}{l}\vec{\leftarrow} \\
\stackrel{5}{\circ}\end{array}$ & 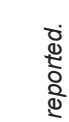 \\
\hline & \multirow{2}{*}{ 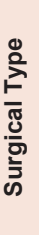 } & 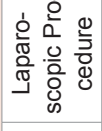 & $\frac{\alpha}{z}$ & 茴 & $\frac{\mathscr{r}}{z}$ & 10 & 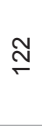 & $\stackrel{*}{\alpha}$ & $\underset{\sim}{\mathbb{Z}}$ & $\stackrel{\mathbb{z}}{z}$ & $\stackrel{*}{\alpha}$ & $\stackrel{\infty}{\text { ల్ల }}$ & ฉ & ৪) & 0 & $\underset{\infty}{\widetilde{\infty}}$ & 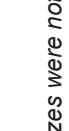 \\
\hline & & 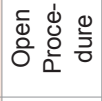 & $\frac{\alpha}{z}$ & พ & $\frac{\alpha}{z}$ & 饮 & $\stackrel{\S}{z}$ & $\stackrel{*}{\alpha}$ & $\stackrel{\nwarrow}{z}$ & $\stackrel{\stackrel{\sim}{\sim}}{ }$ & $\frac{\alpha}{z}$ & $\$$ & 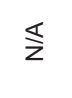 & $\stackrel{\text { pి }}{\leftarrow}$ & 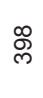 & $\stackrel{g}{ }$ & 离 \\
\hline & \multirow{3}{*}{ 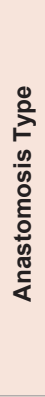 } & 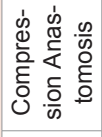 & $\lesssim$ & $\stackrel{\infty}{\infty}$ & $\stackrel{\aleph}{z}$ & 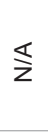 & 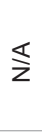 & $\stackrel{\varsigma}{z}$ & $\lesssim$ & $\lesssim$ & $\$$ & 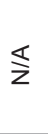 & 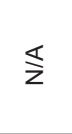 & 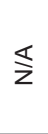 & 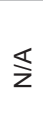 & $\stackrel{\infty}{\infty}$ & \begin{tabular}{l}
5 \\
0 \\
5 \\
0 \\
\multirow{2}{5}{} \\
0 \\
0 \\
0
\end{tabular} \\
\hline & & 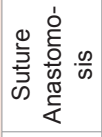 & $\stackrel{\llcorner}{N}$ & 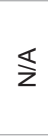 & $\stackrel{\S}{z}$ & $\stackrel{\aleph}{z}$ & $\stackrel{\S}{z}$ & $\stackrel{\infty}{\infty}$ & 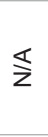 & 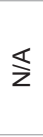 & ৪ & $\stackrel{\nwarrow}{z}$ & 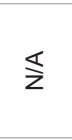 & 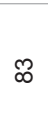 & $\stackrel{\infty}{\sim}$ & 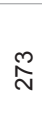 & $\begin{array}{l}0 \\
0 \\
0 \\
0 \\
0 \\
0 \\
0 \\
0 \\
0\end{array}$ \\
\hline & & 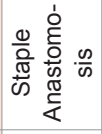 & in & $\stackrel{\infty}{\infty}$ & $\stackrel{2}{\wedge}$ & 8 & 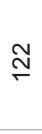 & $\stackrel{\sim}{\sim}$ & $\stackrel{\mathbb{N}}{N}$ & $\stackrel{\mathbb{S}}{\mathrm{I}}$ & ஜి & 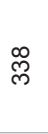 & 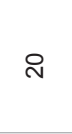 & $\stackrel{g}{\square}$ & ? & $\underset{N}{N}$ & $\frac{\sqrt{0}}{\frac{\pi}{8}} \frac{\sqrt{0}}{\frac{0}{0}}$ \\
\hline & & 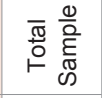 & $\stackrel{2}{1}$ & \& & $\stackrel{m}{\wedge}$ & 8 & 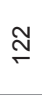 & $\stackrel{\text { L }}{\sim}$ & $\underset{\sim}{\mathbb{J}}$ & $\stackrel{\mathbb{I}}{\stackrel{2}{*}}$ & ஜ̊ & $\stackrel{\infty}{m}$ & $\stackrel{\sim}{ }$ & $\stackrel{\mathbb{N}}{\text { N }}$ & 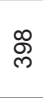 & $\begin{array}{l}\widetilde{N} \\
\text { లె }\end{array}$ & \begin{tabular}{l}
0 \\
\multirow{2}{0}{} \\
8 \\
8
\end{tabular} \\
\hline & & $\begin{array}{l}\text { 哀 } \\
\text { 爱 }\end{array}$ & $\begin{array}{l}\frac{5}{\Phi} \\
\frac{\bar{U}}{0}\end{array}$ & 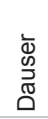 & 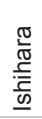 & $\begin{array}{l}\overrightarrow{0} \\
\stackrel{\mathbb{N}}{\geq} \\
\stackrel{2}{\geq}\end{array}$ & 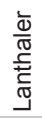 & 胥 & ב & $\stackrel{?}{\stackrel{0}{\varrho}}$ & 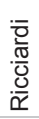 & 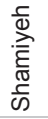 & 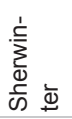 & $\begin{array}{l}\text { 产 } \\
\text { के }\end{array}$ & 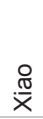 & $\begin{array}{l}\underset{\leftarrow}{5} \\
\stackrel{5}{\vdash}\end{array}$ & $\begin{array}{l}\text { क } \\
\text { के } \\
\text { के } \\
\text { क }\end{array}$ \\
\hline
\end{tabular}


$4.6 \%$ (Table 5). A total of 1,788 of the 2,098 patients (85\%) received intraoperative leak testing. There were 76 post-operative leaks in the sample of patients who received intra-operative leak testing, yielding a leak rate of $4.3 \%$ for the tested group. Of the 76 leaks, 12 occurred in patients with an initially positive intra-operative leak test and 64 postoperative leaks occurred in patients with a negative intra-operative leak test, leading to a significantly higher post-operative anastomotic leak rates within the group of patients with an initially positive leak test $(8.8 \%$ and $3.9 \%, \mathrm{p}=0.006)$. The remaining 21 leaks were observed within the sample of 310 patients who did not receive an intraoperative leak test, corresponding to a post-operative anastomotic leak rate of $6.8 \%$ in this group (Table 5). There was a non-significant

\begin{tabular}{|c|c|c|c|}
\hline \multicolumn{4}{|c|}{ Intraoperative Testing } \\
\hline & $\begin{array}{l}\text { Total } \\
\text { Sample }\end{array}$ & Received Test & Testing Rate \\
\hline All Cases & 3,023 & 2,598 & $85.9 \%$ \\
\hline Stapled Cases* & 2,505 & 2,205 & $88.0 \%$ \\
\hline Sutured Cases* & 235 & 157 & $66.8 \%$ \\
\hline $\begin{array}{l}\text { Compression } \\
\text { Cases }\end{array}$ & 38 & 38 & $100.0 \%$ \\
\hline \multicolumn{4}{|c|}{ Intraoperative Leaks (Tested Cases Only) } \\
\hline & $\begin{array}{l}\text { Total } \\
\text { Sample }\end{array}$ & $\begin{array}{l}\text { Positive Intra- } \\
\text { operative Test }\end{array}$ & $\begin{array}{l}\text { Intraoperative Leak } \\
\text { Rate }\end{array}$ \\
\hline All Cases & 2,598 & 167 & $6.4 \%$ \\
\hline Stapled Cases** & 2,084 & 103 & $4.9 \%$ \\
\hline Sutured Cases** & 258 & 6 & $2.3 \%$ \\
\hline $\begin{array}{l}\text { Compression } \\
\text { Cases }\end{array}$ & 38 & 0 & $0.0 \%$ \\
\hline \multicolumn{4}{|c|}{ Post-operative Leaks } \\
\hline & $\begin{array}{l}\text { Total } \\
\text { Sample }\end{array}$ & Post-operative Leak & $\begin{array}{l}\text { Post-operative Leak } \\
\text { Rate }\end{array}$ \\
\hline All Cases & 3,023 & 160 & $5.2 \%$ \\
\hline $\begin{array}{l}\text { Stapled } \\
\text { Cases }^{* * *}\end{array}$ & 2,661 & 135 & $5.1 \%$ \\
\hline $\begin{array}{l}\text { Sutured } \\
\text { Cases }^{* * *}\end{array}$ & 248 & 24 & $9.7 \%$ \\
\hline $\begin{array}{l}\text { Compression } \\
\text { Cases }\end{array}$ & 38 & 2 & $5.3 \%$ \\
\hline \multicolumn{4}{|c|}{ * Leahy et al. excluded from calculation. } \\
\hline \multicolumn{4}{|c|}{${ }^{* *}$ Chen et al., Leahy et al., and Xiao et al excluded from calculation. } \\
\hline
\end{tabular}

Table 5: Post-operative Leak Rate by Intra-operative Testing.

\begin{tabular}{|l|l|l|l|l|}
\hline & Sample & $\begin{array}{l}\text { Intra-operative } \\
\text { Leaks }\end{array}$ & $\begin{array}{l}\text { Post-operative } \\
\text { Leaks }\end{array}$ & $\begin{array}{l}\text { Rate of Post- } \\
\text { operative } \\
\text { Leaks }\end{array}$ \\
\hline No Testing & 310 & N/A & 21 & $6.8 \%$ \\
\hline Received Testing & 1788 & 136 & 76 & $4.3 \%$ \\
\hline Positive Leak Test & 136 & 12 & $8.8 \%$ \\
\hline $\begin{array}{l}\text { Negative Leak } \\
\text { Test }\end{array}$ & 1652 & 64 & $3.9 \%$ \\
\hline Total & & 62 & \\
\hline
\end{tabular}

Total Sample includes $\mathrm{N}=2,908$ cases from Chen, Ishihara, Ivanov, Li, Ricciardi, Sherwinter, Smith, and Xiao. trend towards a lower post-operative leak rate within the tested group (4.3\% v. $6.8 \%, \mathrm{p}=0.051)$.

\section{Discussion}

The rate of intraoperative anastomotic leaks was estimated within a sample of 13 articles reporting on a total of $\mathrm{N}=3,023$ colorectal resection surgeries. Intra-operative anastomotic testing was found to be widely employed in colon resection surgery with a mean testing rate of $86.5 \%$ for the study. Air insufflation was the most commonly used methodology to test for intra-operative anastomotic leaks, although dye tests and water bubble tests were also employed. When an intraoperative anastomotic leak was identified, correction of the anastomosis was most commonly performed by suture repair followed by takedown and re-anastomosis and diversion. The requirement to use intraoperative leak testing in nine of the study protocols may have resulted in an artificially high estimated rate of leak testing within our sample. Yet, when only those cases where the decision to test was left to the surgeon a similar rate of intra-operative testing was found (82.3\%). A total of 167 intra-operative leaks were identified within 2,598 cases where intra-operative testing was employed, leading to an estimated mean intra-operative anastomotic leak rate of $6.4 \%$. This leak rate is consistent with ranges presented in other publications [3134].

A sub-analysis of those studies that reported on the rate of intra-operative testing and post-operative anastomotic leak within the same population revealed that patients who did not receive leak testing had a trend towards an increased rate of post-operative leaks compared to patients who received testing ( $6.8 \%$ vs. $4.3 \%, \mathrm{p}=0.051)$. Although the definitive causes of post-operative anastomotic leak remains unknown, leak development is believed to be related to anastomotic healing, as opposed to intraoperative leaks which are the result of injury, adhesions, and weak or insufficient anastomosis, related to factors of the surgery itself [35]. Therefore, aside from a minority of cases where an undetected or uncorrected intra-operative leak progresses to a clinical post-operative leak, there is no reason to assume there is a direct relationship between the development of intra-operative and post-operative leaks. Yet, the findings of this and other studies indicate that use of intra-operative leak testing may be helpful in reducing the rate of post-operative leaks [31]. Part of the trend for reduced leaks with testing can be accounted for by prompt identification of weak or insufficient anastomoses allowing for intra-operative repair, thus promoting anastomotic healing and preventing the intra-operative defect from becoming a post-operative leak. The trend observed here towards an increased leak rate of $6.8 \%$ in untested patients compared to $4.3 \%$ in tested patients goes to this point. However, the significantly higher post-operative leak rate of $8.8 \%$ within patients with an initially positive leak test compared to the post-operative leak rate of $3.9 \%$ in patients with a negative leak test suggests there are other factors that contribute to the development of anastomotic leak. These findings indicate that despite correction of the leak at the time of surgery through suturing, re-anastomosis, or diversion a subpopulation of patients remain at an increased risk for anastomotic leak even with the use of anastomotic testing. Although some risk factors for anastomotic leak including male gender, steroid use, obesity, malnutrition, and intraoperative blood loss are known, 
other yet unidentified risk factors certainly exist $[9,35]$. It is possible that the subpopulation of patients with an initially positive leak test who develop a post-operative leak includes patients at higher risk for anastomotic leak, potentially due to comorbidity, changes in the composition of the patient's microbiome, decreased gastrointestinal healing, or increased damage to colorectal tissue $[36,37]$. Our finding that the rate of post-operative anastomotic leak is increased in the population of patients with an initially positive intra-operative leak test, despite intra-operative repair, is consistent with previous reports, and suggests that additional strategies for intraoperative leak repair may be needed for this high risk population [31]. Additional studies to identify patient and surgical characteristics that predispose patients to both intra-operative and post-operative leaks anastomotic leak are certainly warranted, as greater insight into the factors that lead to anastomotic leak could be helpful in managing at risk patients.

This study also included a limited examination of surgical techniques employed in colon resection surgery. There was a heavy skew towards the use of stapled anastomosis in this sample, employed in $89.7 \%$ of cases. Part of the reason for the high rate of staple use was due to seven of the 13 studies including only cases with a stapled anastomosis. Yet even in those studies that included multiple anastomosis types, staples were used in $84.8 \%$ of cases, indicating that study protocol is not the driving force behind staple use. There were no significant differences in the rate of intra-operative leaks across various anastomosis types (e.g. sutured versus stapled). Despite the similar rate of intra-operative leaks, a significantly lower rate of postoperative leaks was observed within the sample of sutured anastomosis compared to stapled anastomosis. These results are in contrast to other studies and may reflect inherent variability between the stapled and sutured cohorts in this sample [32-34]. For instance, the rate of intra-operative testing in the sutured sample was notably lower than that in the stapled sample ( $66.8 \%$ v. $88.0 \%)$. Use of open versus laparoscopic techniques were evenly distributed, with laparoscopic techniques used in just over half $(53.5 \%)$ of cases. In this sample there was a higher rate of both intra-operative and post-operative anastomotic leak within the open surgery group. This finding is not unprecedented, although the results favoring laparoscopic surgery may be partially tied to this sample which includes a variety of procedures, anastomosis sites, and testing protocols [38,39].

A systematic review of the recent literature was performed to assess the current state of intra-operative anastomotic leak testing in colorectal resection surgery. This study found an intra-operative leak rate of $6.4 \%$ within the sample of $\mathrm{N}=2,598$ patients who received an intraoperative leak test during colorectal resection surgery. The various surgical methodologies, procedures performed, and patient samples across the studies is a limitation of this review and leads to a high level of variability across the sample, which likely accounts for the wide range of intra-operative $(0.0 \%-23.3 \%)$ and post-operative $(0.8 \%-15.0 \%)$ leak rates observed across studies. Further, as noted in other studies, the definition for anastomotic leak and other postoperative complications varies across surgical sites and institutions reducing the level of accuracy in estimating anastomotic leak rates [35,40]. Although 10 articles had a similar definition of anastomotic leak there were six slightly different definitions for anastomotic leak; further three manuscripts did not provide a definition for anastomotic leak. Use of different definitions for anastomotic leak across studies is less of a problem in the assessment of intra-operative anastomotic leak, as these leaks are defined by the testing methodology used. Although the results from this systematic review study combine leak rates across studies using several different types of resection procedures, intraoperative testing methodologies, and resection protocols, it remains one of the first studies to try and estimate a mean rate of anastomotic leaks during colorectal resection surgery. Additional studies to assess the relative impact of different testing methodologies, patient related factors, and surgical characteristics are needed to provide a more comprehensive assessment of the impact of intraoperative leak testing on patient outcomes in colorectal resection surgery.

\section{Conflict of Interest}

Ethicon funded this study. A.S., S.K.G, and E.F. are employees of Johnson \& Johnson and are Johnson \& Johnson stockholders. B.L.B and C.R. are employees of Health Analytics, which received research support from Johnson \& Johnson to conduct this study.

\section{References}

1. Kwon S, Morris A, Billingham R, Frankhouse J, Horvath K, et al. (2012) Routine leak testing in colorectal surgery in the Surgical Care and Outcomes Assessment Program. Arch Surg 147: 345-351.

2. Branagan G, Finnis D (2005) Wessex Colorectal Cancer Audit Working G. Prognosis after anastomotic leakage in colorectal surgery. Dis Colon Rectum 48: 1021-1026.

3. Fouda E, El Nakeeb A, Magdy A, Hammad EA, Othman G, et al. (2011) Early detection of anastomotic leakage after elective low anterior resection. J Gastrointest Surg 15: 137-144.

4. Bellows CF, Webber LS, Albo D, Awad S, Berger DH (2009) Early predictors of anastomotic leaks after colectomy. Tech Coloproctol 13: 41-47.

5. Golub R, Golub RW, Cantu R, Jr., Stein HD (1997) A multivariate analysis of factors contributing to leakage of intestinal anastomoses. J Am Coll Surg 184: 364-372.

6. Murrell ZA, Stamos MJ (2006) Reoperation for anastomotic failure. Clin Colon Rectal Surg 19: 213-216.

7. Walker KG, Bell SW, Rickard MJ, Mehanna D, Dent OF, et al. (2004) Anastomotic leakage is predictive of diminished survival after potentially curative resection for colorectal cancer. Ann Surg 240: 255-259.

8. Petersen S, Freitag M, Hellmich G, Ludwig K (1998) Anastomotic leakage: impact on local recurrence and survival in surgery of colorectal cancer. Int $\mathrm{J}$ Colorectal Dis 13: 160-163.

9. Daams F, Luyer M, Lange JF (2013) Colorectal anastomotic leakage: aspects of prevention, detection and treatment. World J Gastroenterol 19: 2293-2297.

10. Lindgren R, Hallbook O, Rutegard J, Sjodahl R, Matthiessen P (2011) What is the risk for a permanent stoma after low anterior resection of the rectum for cancer? A six-year follow-up of a multicenter trial. Dis Colon Rectum 54: 41-47.

11. Chambers WM, Mortensen NJ (2004) Postoperative leakage and abscess formation after colorectal surgery. Best Pract Res Clin Gastroenterol 18: 865880.

12. Buchs NC, Gervaz P, Secic M, Bucher P, Mugnier-Konrad B, et al. (2008) Incidence, consequences, and risk factors for anastomotic dehiscence after colorectal surgery: a prospective monocentric study. Int $\mathrm{J}$ Colorectal Dis 23: 265-270. 
13. Hammond J, Lim S, Wan Y, Gao X, Patkar A (2014) The burden of gastrointestinal anastomotic leaks: an evaluation of clinical and economic outcomes. J Gastrointest Surg 18: 1176-1185.

14. Rios J, Murillo C, Carrasco G, Humet C (2003) Increase in costs attributable to surgical infection after appendicectomy and colectomy. Gac Sanit 17: 218225 .

15. Boccola MA, Lin J, Rozen WM, Ho YH (2010) Reducing anastomotic leakage in oncologic colorectal surgery: an evidence-based review. Anticancer Res 30: 601-607.

16. Ricciardi R, Roberts PL, Marcello PW, Hall JF, Read TE, et al. (2009) Anastomotic leak testing after colorectal resection: what are the data? Arch Surg 144: 407-411.

17. Cancer SoAGRoCCaR (2012) Guidelines for Laparoscopic Resection of Curable Colon and Rectal Cancer.

18. Nygren J, Thacker J, Carli F, Fearon KC, Norderval S, et al. (2012) Guidelines for perioperative care in elective rectal/pelvic surgery: Enhanced Recovery after Surgery (ERAS(R)) Society recommendations. Clin Nutr 31: 801-816.

19. Dauser B, Braunschmid T, Ghaffari S, Riss S, Stift A, et al. (2013) Anastomotic leakage after low anterior resection for rectal cancer: comparison of stapled versus compression anastomosis. Langenbecks Arch Surg 398: 957-964.

20. Ishihara S, Watanabe T, Nagawa H (2008) Intraoperative colonoscopy for stapled anastomosis in colorectal surgery. Surg Today 38: 1063-1065

21. Ivanov D, Cvijanovic R, Gvozdenovic L (2011) Intraoperative air testing of colorectal anastomoses. Srp Arh Celok Lek 139: 333-338.

22. Lanthaler M, Biebl M, Mittermair R, Ofner D, Nehoda H (2008) Intraoperative colonoscopy for anastomosis assessment in laparoscopically assisted leftsided colon resection: is it worthwhile? J Laparoendosc Adv Surg Tech A 18 : 27-31.

23. Leahy J, Schoetz D, Marcello P, Read T, Hall J, Roberts P, et al. (2014) What is the risk of clinical anastomotic leak in the diverted colorectal anastomosis? J Gastrointest Surg 18: 1812-816.

24. Li VK, Wexner SD, Pulido N, Wang H, Jin HY, et al. (2009) Use of routine intraoperative endoscopy in elective laparoscopic colorectal surgery: can it further avoid anastomotic failure? Surg Endosc 23: 2459-2465.

25. Lieto E, Orditura M, Castellano P, Pinto M, Zamboli A, et al. (2011) Endoscopic intraoperative anastomotic testing may avoid early gastrointestinal anastomotic complications. A prospective study. J Gastrointest Surg 15: 145152

26. Shamiyeh A, Szabo K, Ulf Wayand W, Zehetner J (2012) Intraoperative endoscopy for the assessment of circular-stapled anastomosis in laparoscopic colon surgery. Surg Laparosc Endosc Percutan Tech 22: 65-67.

27. Sherwinter DA, Gallagher J, Donkar T (2013) Intra-operative transanal near infrared imaging of colorectal anastomotic perfusion: a feasibility study.
Colorectal Dis 15: 91-96

28. Smith S, McGeehin W, Kozol RA, Giles D (2007) The efficacy of intraoperative methylene blue enemas to assess the integrity of a colonic anastomosis. BMC Surg 7: 15.

29. Xiao L, Zhang WB, Jiang PC, Bu XF, Yan Q, et al. (2011) Can transanal tube placement after anterior resection for rectal carcinoma reduce anastomotic leakage rate? A single-institution prospective randomized study. World J Surg 35: 1367-1377.

30. Chen CW, Chen MJ, Yeh YS, Tsai HL, Chang YT, et al. (2013) Intraoperative anastomotic dye test significantly decreases incidence of anastomotic leaks in patients undergoing resection for rectal cancer. Tech Coloproctol 17: 579583.

31. Wu Z, van de Haar RC, Sparreboom CL, Boersema GS, Li Z, et al. (2016) Is the intraoperative air leak test effective in the prevention of colorectal anastomotic leakage? A systematic review and meta-analysis. Int J Colorectal Dis 31: 1409-1417.

32. Lustosa SA, Matos D, Atallah AN, Castro AA (2002) Stapled versus handsewn methods for colorectal anastomosis surgery: a systematic review of randomized controlled trials. Sao Paulo Med J 120: 132-136.

33. MacRae HM, McLeod RS (1998) Handsewn vs. stapled anastomoses in colon and rectal surgery: a meta-analysis. Dis Colon Rectum 41: 180-189.

34. Neutzling CB, Lustosa SA, Proenca IM, da Silva EM, Matos D (2012) Stapled versus handsewn methods for colorectal anastomosis surgery. Cochrane Database Syst Rev CD003144.

35. Kirchhoff P, Clavien PA, Hahnloser D (2010) Complications in colorectal surgery: risk factors and preventive strategies. Patient Saf Surg 4: 5.

36. Bosmans JW, Jongen AC, Bouvy ND, Derikx JP (2015) Colorectal anastomotic healing: why the biological processes that lead to anastomotic leakage should be revealed prior to conducting intervention studies. BMC Gastroenterol 15: 180.

37. Shogan BD, Smith DP, Christley S, Gilbert JA, Zaborina O, et al. (2014) Intestinal anastomotic injury alters spatially defined microbiome composition and function. Microbiome 2: 35 .

38. Braga M, Vignali A, Gianotti L, Zuliani W, Radaelli G, et al. (2002) Laparoscopic versus open colorectal surgery: a randomized trial on shortterm outcome. Ann Surg 236: 759-766.

39. Kang CY, Halabi WJ, Chaudhry OO, Nguyen V, Pigazzi A, et al. (2013) Risk factors for anastomotic leakage after anterior resection for rectal cancer. JAMA Surg 148: 65-71.

40. Bruce J, Krukowski ZH, Al-Khairy G, Russell EM, Park KG (2001) Systematic review of the definition and measurement of anastomotic leak after gastrointestinal surgery. Br J Surg 88: 1157-1168.

Copyright: (c) 2016 Schiff A, et al. This is an open-access article distributed under the terms of the Creative Commons Attribution License, which permits unrestricted use, distribution, and reproduction in any medium, provided the original author and source are credited. 